Pesq. Vet. Bras. 36(4):351-355, abril 2016

DOI: $10.1590 / \mathrm{S} 0100-736 \mathrm{X} 2016000400016$

\title{
Morfologia da língua do cervo do pantanal (Blastocerus dichotomus) ${ }^{1}$
}

\author{
Márcia R.F. Machado², Maria R. Pacheco ${ }^{2}$, Leonardo M. Leal ${ }^{2 *}$, Leandro L. Martins ${ }^{2}$, \\ Ana C.G. dos Reis ${ }^{2}$ e José M.B. Duarte ${ }^{3}$
}

\begin{abstract}
Machado M.R.F., Pacheco M.R., Leal L.M., Martins L.L., Dos Reis A.C.G. \& Duarte J.M.B. 2016. [Morphology of the tongue of the Marsh deer (Blastocerus dichotomus).] Morfologia da língua do cervo do pantanal (Blastocerus dichotomus). Pesquisa Veterinária Brasileira 36(4):351-355. Departamento de Morfologia e Fisiologia Animal, Faculdade de Ciências Agrárias e Veterinárias, Universidade Estadual Paulista, Via de Acesso Paulo Donato Castellane s/n, Jaboticabal, SP 14884-900, Brazil. Email: leonardo.vet@hotmail.com

The aim was to describe the morphology of the tongue of the Marsh deer (Blastocerus dichotomus), the largest deer of the Brazilian fauna, since there is little detailed information on their morphology. Tongues of eight adult Marsh deers, belonging to Projeto cervo-do-pantanal de Porto Primavera were analyzed for their macroscopic aspects and by light microscopy. The Marsh deer tongue occupies most of the oral cavity, where the root and body are fixed caudally by the hyoid bone, and in its middle portion by the frenulum linguae; its free apex is flat and plane, has little prominent torus lingae and there is no demarcation of fossa linguae. The lateral and ventral surfaces are covered by a thin mucosa; however the dorsal surface is covered by thick mucosa, although soft. On the dorsal surface are the papillae: filiform, conical, lenticular, fungiform and vallate. Histologically was found that the mucosa has a stratified squamous epithelium, the lamina propria consists of connective tissue rich in collagen fibers arranged in several directions, where there is abundant vascularization and accumulation of lymphoid tissue.
\end{abstract}

INDEX TERMS: Tongue, Marsh deer, Blastocerus dichotomus, anatomy, ruminants, wild mammals.

RESUMO.- Objetivou-se descrever a morfologia da língua do cervo do pantanal (Blastocerus dichotomus), o maior cervídeo da fauna brasileira, pois poucas são as informações detalhadas sobre sua morfologia. Línguas e fragmentos linguais de oito cervos do pantanal, adultos, provenientes do Projeto Cervo-do-Pantanal de Porto Primavera foram analisados quanto aos seus aspectos macroscópicos e à microscopia de luz. A língua do cervo do pantanal ocupa grande parte da cavidade oral, onde a raiz e o corpo estão fixados caudalmente pelo osso hióide e, em sua porção média, pelo frênulo lingual; seu ápice, achatado e plano é livre; apresenta torus lingual pouco proeminente, não havendo delimitação da fossa lingual. Na superfície dorsal encontram-se as seguintes pa-

\footnotetext{
${ }^{1}$ Recebido em 13 de maio de 2015.

Aceito para publicação em 18 de janeiro de 2016.

${ }^{2}$ Departamento de Medicina Veterinária, Faculdade Ingá, Unidade de Ensino Superior Ingá (Uningá), Rodovia PR-317 no 6114, Parque Industrial Duzentos, Maringá, PR 87035-510, Brasil. *Autor para correspondência: leonardo.vet@hotmail.com

${ }^{3}$ Departamento de Zootecnia, Faculdade de Ciências Agrárias e Veterinárias, Unesp, Via de Acesso Paulo Donato Castellane s/n, Jaboticabal, SP 14884-900, Brasil.
}

pilas: filiformes, cônicas, lenticulares, fungiformes e valadas. Histologicamente verificou-se que a mucosa reveste-se de epitélio estratificado pavimentoso queratinizado, a lâmina própria constitui-se de tecido conjuntivo, rico em fibras colágenas dispostas em várias direções, onde se verifica abundante vascularização, além de acúmulo de tecido linfático.

TERMOS DE INDEXAÇÃO: Língua, cervo do pantanal, Blastocerus dichotomus, anatomia, ruminants, mamíferos selvagens, ruminantes.

\section{INTRODUÇÃO}

O cervo-do-pantanal (Blastocerus dichotomus) é um morador bem adaptado às regiões de várzea, áreas alagadas e beira de rios, pois esse ambiente propicia boa oferta de alimentos; segurança, já que se locomove em terrenos alagados melhor que a onça, seu grande inimigo natural; e a necessidade de se refrigerar. Por estas razões, a preservação do meio ambiente é o primeiro grande passo para evitar a extinção desses animais (Fonseca 2002). Através da Portaria no 1.522 , de 19 de dezembro de 1.989 e da Portaria $n^{0}$ 45-N, de 27 de abril de 1.992, o IBAMA tornou pública a lista oficial de espécies da fauna brasileira ameaçada de extinção, na qual consta o cervo-do-pantanal (Ibama 2003). 
A língua é um órgão muscular que ocupa grande parte da cavidade oral, sendo composta pela raiz e corpo que se fixam caudalmente pelo osso hioide e em sua porção média pelo frênulo lingual, seu ápice é livre (Nickel et al. 1989, Dyce et al. 2004). Nos ruminantes domésticos, o ápice lingual é pontiagudo nos bovinos, contudo, nos pequenos ruminantes esta característica é bem menos pronunciada (May 1970, Nickel et al. 1989, Dyce et al. 2004). 0 torus lingual é uma estrutura elíptica que caracteriza a porção caudal do dorso da língua encontrada no bovino, no ovino e nos ruminantes em geral (McLeod 1960, May 1970, Habel 1986, Nickel et al. 1989). Geralmente nos herbívoros domésticos a mucosa da língua é áspera, coberta em grande parte por uma série de papilas linguais, caracterizadas como filiformes, fungiformes e valadas, não se observando nesses animais presença de papilas folhadas (Qayyum \& Beg 1975, Chamorro et al. 1986, Kobayashi et al. 1995, Dyce et al. 2004).

Junqueira \& Carneiro (2008), para os humanos, citam que a língua é formada por uma massa de tecido muscular estriado, recoberto por uma mucosa cuja estrutura varia de acordo com a região do órgão. As fibras musculares estriadas formam feixes, que se entrecruzam nos três planos do espaço, separados por tecido conjuntivo. A mucosa apresenta-se fortemente aderida à massa muscular, devido à penetração do tecido conjuntivo da lâmina própria entre as fibras musculares.

Assim, com o intuito de melhor conhecer as estruturas do aparelho digestório do Blastocerus dichotomus, o cervo do pantanal, uma vez que este sistema está diretamente relacionado à adaptação das espécies no seu habitat e devido à falta de informações detalhadas sobre a morfologia destes cervídeos, objetivou-se descrever a morfologia da língua destes animais, órgão com relevantes funções na alimentação e na percepção gustativa.

\section{MATERIAL E MÉTODOS}

A presente metodologia foi aprovada pela Comissão de Ética no Uso de Animais (CEUA) da Faculdade de Ciências Agrárias e Veterinárias (FCAV-Unesp), Jaboticabal-SP, de acordo com os princípios éticos na experimentação animal adotado pelo Conselho Nacional de Controle de Experimentação Animal (CONCEA) sob o número de protocolo 020115/13.

Para o estudo macroscópico da língua do Cervo do Pantanal (Blastocerus dichotomus), observou-se a localização, forma e fixação deste órgão mediante dissecção e inspeção visual em oito animais adultos, pertencentes ao projeto Projeto Cervo-do-Pantanal de Porto Primavera, (parceria entre FCAV-Unesp e Companhia Energética de São Paulo - CESP, sob licença para Captura/Coleta/ Transporte/Exposição número 013/2001-DIFAC/DIREC) e que vieram a óbito no período de quarentena por ocasião da inundação da área de influencia da Usina Hidroelétrica de Porto Primavera, SP.

Observou-se a localização e fixação da língua, que em seguida, mediante dissecação, foi individualizada e mensurada com auxílio de fita métrica e ainda verificou-se a disposição e a localização das papilas linguais, procedendo-se a documentação fotográfica.

Para a análise à microscopia de luz, colheu-se segmentos de diferentes regiões da língua que foram colocados em fixador de McDowell, que consiste em uma solução de paraformaldeído a 4\% e glutaraldeído a 1\% em tampão fosfato de Sorensen 0,1 M pH 7, 2, para a fixação de 24 horas.
Posteriormente, parte do material foi incluído em Historresina (Historesin Jung - 70 -2218 -500), e outra parte incluído em parafina, mediante a rotina histológica convencional.

$\mathrm{Na}$ fase seguinte o material foi seccionado em micrótomo automático (Micrótomo Rotativo Universal, modelo AUTOCUT 2055), utilizando navalhas de vidro e de aço descartáveis. Os cortes foram estendidos em água destilada fria e posteriormente montados em lâminas.

Tanto os cortes obtidos do material incluído em resina plástica, quanto os obtidos do material incluído em parafina, foram corados em hematoxilina eosina e posteriormente fotomicrografados.

\section{RESULTADOS}

A língua do cervo do pantanal (Blastocerus dichotomus) ocupa grande parte da cavidade oral, está fixada caudalmente pelo osso hióide e na porção média pelo frênulo lingual. 0 ápice, achatado e plano, é livre; o corpo e a raiz da língua são fixos, o torus lingual não é muito proeminente e dessa forma não se verifica presença de fossa lingual (Fig.1).

As superfícies, lateral e ventral desse órgão são revestidas por fina mucosa; no dorso, devido à cornificação do epitélio, a mucosa é mais espessa, estão presentes as papilas mecânicas filiformes, cônicas e lenticulares, além das papilas gustativas fungiformes e valadas.

As papilas filiformes espalham-se por todo o dorso da língua e são delicadas, conferindo aspecto liso a este órgão (Fig.1). As papilas cônicas e lentiformes aparecem por toda a extensão do torus lingual, embora as lentiformes estejam presentes em menor quantidade. Já as papilas fungiformes estão espalhadas por toda a língua, na região dorsal, ápice, torus lingual e faces laterais (Fig.1). Verificou-se ainda a presença de aproximadamente oito papilas valadas na re-

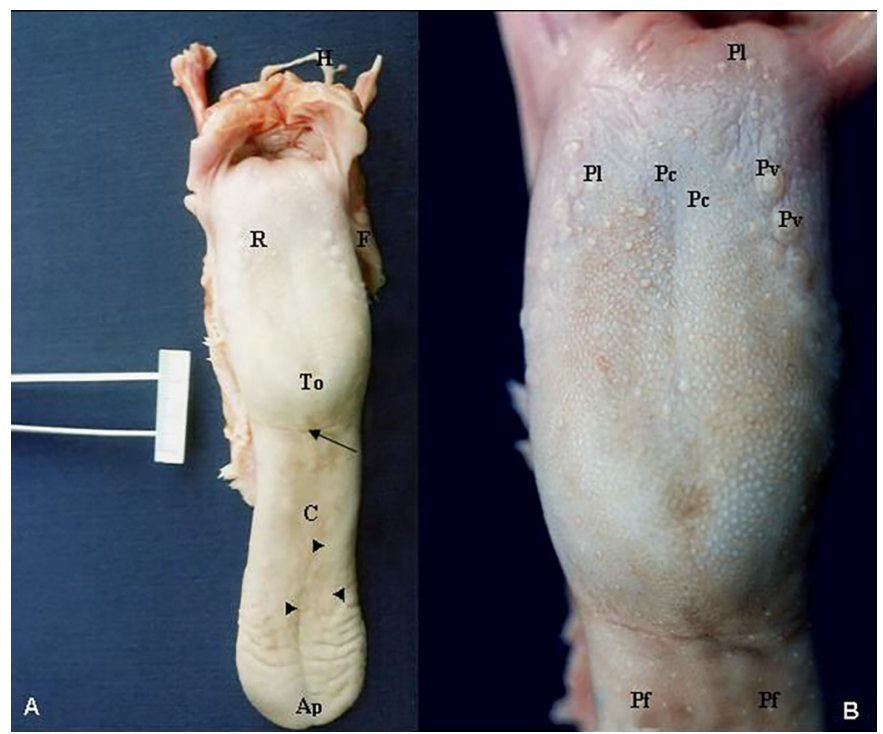

Fig.1. (A) Língua de um cervo de pantanal adulto (Blastocerus dichotomus) indicando o ápice espatulado (Ap), o corpo (C), a raiz $(\mathrm{R})$, parte do osso hióide $(\mathrm{H})$, parte do frênulo lingual $(\mathrm{F})$, o torus lingual pouco pronunciado (To), a fossa lingual (seta) que nesta espécie não é muito profunda. Observar as papilas filiformes, que conferem o aspecto áspero e as papilas fungiformes (cabeça de seta), ambas espalhadas por todo o dorso do órgão. (B) Detalhe para da porção caudal do órgão onde se observam as papilas cônicas (Pc); papilas lentiformes (Pl); papilas fungiformes (Pf) e papilas valadas (Pv). 
gião lateral, direita e esquerda, da porção caudal do torus lingual do cervo do pantanal (Fig.1).

Ao estudo histológico observou-se que este órgão é recoberto por mucosa revestida de epitélio estratificado pavimentoso queratinizado (Fig.2). Abaixo do epitélio lingual, formando a lâmina própria ou córion, constatou-se presença de tecido conjuntivo amplamente vascularizado, rico em fibras colágenas dispostas em várias direções com acúmulo de tecido linfático; sob a lâmina própria, verificou-se expressiva massa de tecido muscular estriado esquelético com feixes musculares dispostos longitudinal e tranversalmente, a estes feixes entremeavam-se fibras colágenas, vasos, fascículos nervosos, células adiposas e glândulas salivares linguais mucosas e serosas (Figs.3 e 4).

Na mucosa da língua do cervo do pantanal foram observadas elevações coriepiteliais formando as seguintes papilas linguais: filiformes, lenticulares, fungiformes e circunvaladas. Histologicamente a papila filiforme do cervo do pantanal apresentava-se em forma de cone, revestido por queratina As papilas fungiformes do cervo do pantanal estavam revestidas por epitélio estratificado pavimentoso

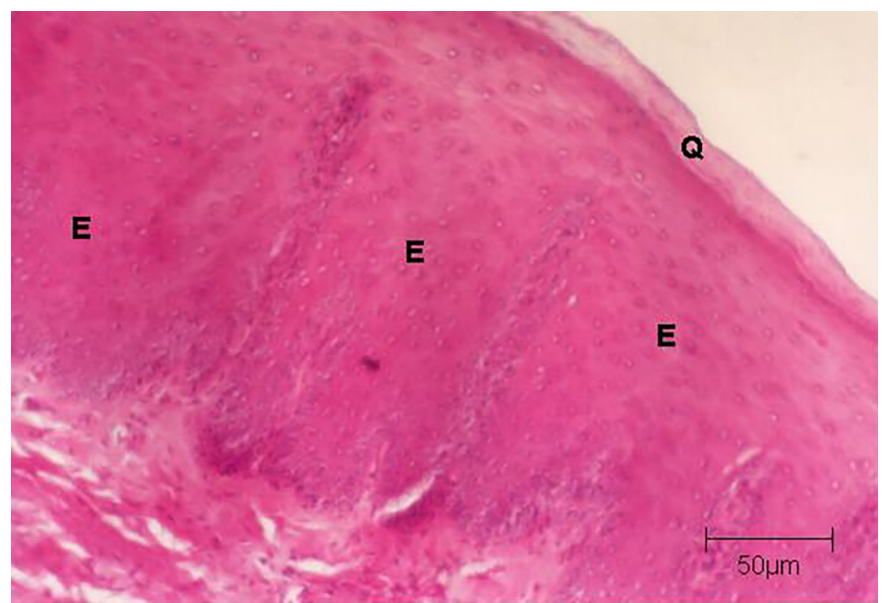

Fig. 2. Língua de um cervo do pantanal (Blastocerus dichotomus) adulto indicando o epitélio estratificado pavimentoso (E) queratinizado (Q). HE, obj.10x.

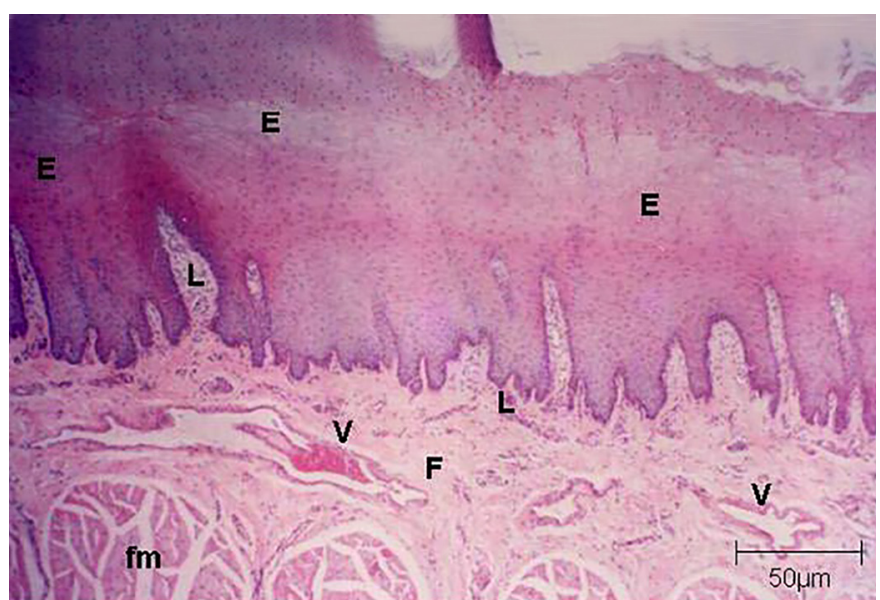

Fig.3. Língua de um cervo do pantanal (Blastocerus dichotomus) adulto indicando o epitélio (E) e abaixo deste, formando a lâmina própria, fibras colágenas (F), acúmulo de tecido linfático (L), feixes musculares (fm) e vasos (V). HE, obj.10x.

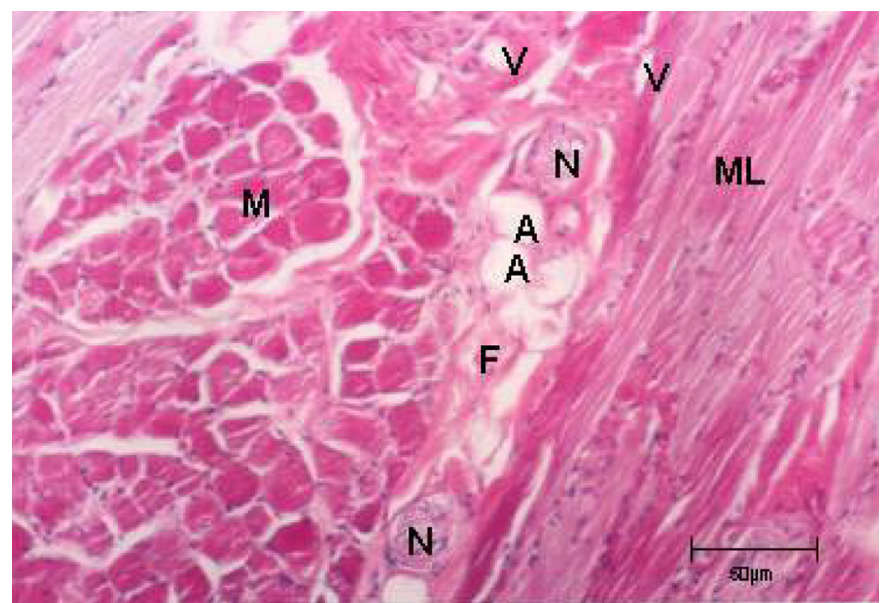

Fig.4. Língua de um cervo do pantanal (Blastocerus dichotomus) adulto, indicando fibras musculares dispostas longitudinalmente (ML); fibras musculares dispostas transversalmente $(\mathrm{M})$; fibras colágenas $(\mathrm{F})$; vasos $(\mathrm{V})$; fascículos de nervos $(\mathrm{N})$; células adiposas $(\mathrm{A})$ e glândulas salivares linguais mucosas (M). HE, obj.10x.

queratinizado e continham vários corpúsculos gustativos. Os achados sobre as papilas lentiforme no cervo do pantanal revelaram que elas revestiam-se por epitélio estratificado pavimentoso e possuíam um centro de tecido conjuntivo denso e regular. Quanto às papilas circunvaladas, no cervo do pantanal estas têm o formato achatado, sendo circundadas por um sulco; apresentam numerosos corpúsculos gustativos, glândulas serosas túbulo alveolares ramificadas e glândulas mucosas.

\section{DISCUSSÃO}

Ao se analisar a localização e fixação da língua do cervo do pantanal (Blastocerus dichotomus) verificou-se que estas características assemelham-se às da língua dos ruminantes e pequenos ruminantes domésticos (May 1970, Nickel et al. 1989, Dyce et al. 2004) e ruminantes selvagens (Saber 1991). Entretanto, sua forma difere, em parte, da língua de todos esses animais, pois nos cervos do pantanal o tórus lingual é pouco desenvolvido e não se verifica a presença da fossa lingual, contudo, a forma do ápice lingual é a mesma observada no gamo e no cervo vermelho (Saber 1991), diferindo das observações de May (1970), Nickel et al. (1989) e Dyce et al. (2004) para a língua do bovino e do ovino.

As características da mucosa lingual do cervo do pantanal são similares a das línguas dos ruminantes domésticos e selvagens (Nickel et al. 1989, Saber 1991), embora Nickel et al. (1989) façam alusão à presença de papilas folhadas na língua dos bovinos, estrutura que não foi observada por Saber (1991) em ruminantes selvagens e neste estudo para o cervo do pantanal.

Verificou-se que o revestimento epitelial da língua do cervo do pantanal é moderadamente queratinizado diferindo das colocações de Nickel et al. (1989) que descrevem a presença de epitélio lingual fortemente queratinizado para os ruminantes domésticos. Também diferem dos relatos feitos para o mouse deer por Agungpriyono et al. (1995) ao registrarem que a língua destes animais apresenta fraca queratinização da cobertura epitelial. 
Segundo Dellmann \& Brown (1982) e Banks (1992) ao se referirem aos ruminantes domésticos e Junqueira \& Carneiro (2008) ao homem em seu tratado de histologia básica, a queratinização do epitélio que reveste a mucosa lingual é variável apresentando vários graus, tal fator, provavelmente, está relacionado à adaptação funcional do indivíduo.

A ocorrência do arranjo dos feixes musculares nas direções longitudinais, transversal e vertical, verificada na arquitetura lingual do cervo do pantanal, confere ao órgão sua movimentação e firmeza (Banks 1992, Dyce et al. 2004). Por outro lado, a organização dos feixes musculares intercalados por fibras colágenas e por células adiposas conferem consistência peculiar para este órgão, este armazenamento adiposo também é muito resistente à mobilização na inanição (Dyce et al. 2004).

Especificamente às papilas linguais do cervo do pantanal, as filiformes são diferentes das encontradas nos bovinos, pois nestes animais se apresentam muito cornificadas (Nickel et al. 1989). Embora a língua dos pequenos ruminantes seja bem menos áspera que a dos ruminantes (Habel 1986, Nickel et al. 1989), não é tão macia como a do cervo do pantanal. Nos ruminantes selvagens, estas papilas têm as mesmas características encontradas para o cervídeo deste estudo, entretanto não se observa neste cervídeo, papila filiforme de comprimento expressivo como relatou Saber (1991) para o cervo vermelho.

À microscopia de luz verificou-se que a papila filiforme da língua do cervo do pantanal, diferentemente dos ruminantes domésticos (Dellmann \& Brown 1982; Banks, 1992), não é muito pronunciada, não apresenta ápice em direção caudal e tampouco tem revestimento espesso de queratina. Já no mouse deer, esta papila possui escasso revestimento de queratina (Agungpriyono et al. 1995). Também não se observaram corpúsculos gustativos nas papilas filiformes do cervo do pantanal conforme descrições de Junqueira \& Carneiro (2008).

As papilas filiformes são consideradas papilas mecânicas (Nickel et al. 1989, Banks 1992, Dyce et al. 2004) uma vez que o arranjo dessas papilas promove à lingua uma superfície adaptada aos seus movimentos e à apreensão do alimento (Svejda \& Skach 1975, Yamada et al. 1983).

A distribuição difusa das papilas cônicas no torus lingual do cervo do pantanal difere da localização concentrada que essas papilas assumem em certas regiões dessa estrutura no cervo montês, cervo vermelho e gamo (Saber 1991). Não se observou a presença dessas papilas espalhadas entre as papilas filiformes como relatadas para os bovinos e pequenos ruminantes (Nickel et al. 1989; Dyce et al. 2004).

Da mesma forma que se observou nos ruminantes selvagens (Saber, 1991), bovinos e pequenos ruminantes (Mcleod et al. 1960, May 1970, Nickel et al. 1989, Habel 1986), as papilas lentiformes do cervo do pantanal estavam distribuídas por todo o torus lingual e as fungiformes encontravam-se espalhadas por toda a língua, contudo, não se observou papilas lentiformes pontiagudas no cervo ora estudado, conforme relatos de Mcleod et al. (1960) para os ruminantes.
O número de papilas valadas encontradas na língua do cervo do pantanal é semelhante ao da língua do bovino (Mcleod et al. 1960, Nickel et al. 1989) e do cervo montês (Saber 1991), sendo inferior ao citado para os pequenos ruminantes, (May 1970, Nickel et al. 1989), para os caprinos (Habel 1986, Nickel et al. 1989) e ao que Saber (1991) relatou para o cervo vermelho, gamo e carneiro selvagem.

Não se registrou a presença de papila folhada rudimentar na língua do cervo conforme os registros de Nickel et al. (1989) para os bovinos.

As papilas linguais, tanto no cervídeo em questão quanto nos animais domésticos (Dellmann \& Brown 1982, Banks 1992), caracterizam-se como elevações coriepiteliais na superfície da língua.

As observações ora verificadas para as papilas fungiformes contrariam as citações de Dellmann \& Brown (1982) ao afirmarem, para os ruminantes, a ocorrência escassa de corpúsculo gustativo e a ausência de revestimento de queratina nestas papilas; entretanto, Banks (1992) apenas mencionou, para esses mesmos animais, que essas papilas não eram muito queratinizadas e Junqueira \& Carneiro (2008) relataram que as papilas fungiformes podem apresentar corpúsculos gustativos. Já Agungpriyono et al. (1995) registraram a presença de corpúsculos gustativos no epitélio das papilas fungiformes do mouse deer.

No cervo do pantanal as papilas linguais lentiformes apresentam estrutura semelhante à dos ruminantes domésticos (Dellmann \& Brown 1982). Banks (1992) relata que essas papilas lenticulares ou cônicas desempenham funções mecânicas.

As papilas circunvaladas da língua do cervo do pantanal têm constituição semelhante à dos ruminantes domésticos (Dellmann \& Brown 1982, Banks 1992) e à do mouse deer (Agungpriyono et al. 1995).

\section{REFERÊNCIAS}

Agungpriyono S., Yamada J., Kitamura N., Nisa C., Sigit K. \& Yamamoto Y. 1995. Morphology of the dorsal lingual papillae in the lesser mouse deer Tragulus javanicus. J. Anat. 187:635-640.

Banks W.J. 1992. Histologia Veterinária Aplicada. 2ª ed. Manole, São Paulo. 629 p.

Chamorro C.A., Paz P., Sandoval J. \& Fernandez J.G. 1986. Comparative scanning electron microscopic study of the lingual papillae in two species of domestic mammals (Equus caballus and Bos taurus). Acta Anatomica 125:83-87.

Dellmann H.D. \& Brown E.M. 1982. Histologia veterinária. Guanabara Koogan, Rio de Janeiro. 397p.

Dyce J.M., Sack W.O. \& Wesing C.I.G. 2004. Tratado de Anatomia Veterinária. 5a ed. Guanabara Koogan, Rio de Janeiro. 813p.

Fonseca C. 2002. Cuidar do Meio ambiente é Preservar a Qualidade de Vida. Disponível em <wysswyg://32/http://www.coelhodafonseca. com.br/SuplementoEstado/SuplementoMateria.asp> Acesso em 13 dez. 2002.

Habel R. 1986. Ruminant digestive system, p.809-811. In: Getty R. (Ed.), Anatomia dos Animais Domésticos. 5a ed. Guanabara Koogan, Rio de Janeiro. 2048p.

Ibama 2003. Instituto Brasileiro de Meio Ambiente e Recursos Naturais Renováveis. Disponível em <http://www.ibama.gov.br/> Acesso em 20 jan. 2003.

Junqueira L.C. \& Carneiro J. 2008. Histologia Básica. 11ª ed. Guanabara Koogan, Rio de Janeiro. 524p. 
Kobayashi K., Kumakura M. \& Takahashi M. 1995.Comparative observations on lingual papillae and their connective tissue cores in three primates: a scanning electron microscopic study. Italian J. Anat. Embryol. 100:349-358.

May N.D.S. 1970. The Anatomy of the Sheep. 3rd ed. University of Queensland Press, Melbourne. 369p.

Mcleod W.M., Trotter D.M. \& Lamb J.W. 1960. Bovine Anatomy. 2nd ed. Burgess Publishing Company, Minneapolis. 267p.

Nickel R., Schummer A., Seiferle E. \& Sack W.O. 1989. The Viscera of the Domestic Mammals. Verlag Paul Parey, Berlin. 401p.
Qayyum M.A. \& Beg M.A. 1975. Anatomical and neurohistological observations on the tongue of the Indian goat, Capra aegagrus. Acta Anatomica 93:554-567.

Saber A.S. 1991. The tongue of four European wild ruminant species: morphology and extrinsic muscles. Assiut Vet. Med. J. 24:10-19.

Svejda J. \& Skach M. 1975. The three-dimensional image of the lingual papillae. Folia Morphologica 23:145-149.

Yamada J., Calingasan N., Kitamura N. \& Yamashita T. 1983. Comparative scanning electron microscopic study of the lingual filiform papillae of some domestic animals. Philippine J. Vet. Med. 22:1-6. 